\title{
MORFOANATOMIA E DESENVOLVIMENTO DE FRUTOS E SEMENTES DE Dodonea viscosa (L.) Jacquin (SAPINDACEAE) ${ }^{1}$
}

\author{
ADELITA APARECIDA SARTORI PAOLI ${ }^{2}$, JANAINA SARTI ${ }^{3}$
}

\begin{abstract}
RESUMO - São descritos aspectos morfológicos e estruturais dos frutos e sementes, em desenvolvimento, de Dodonea viscosa (L.) Jacquin (Sapindaceae), visando o conhecimento dos tegumentos, endosperma e embrião.
\end{abstract}

Termos para indexação: morfologia, pericarpo, Sapindaceae.

MORPHOLOGY AND ANATOMY OF THE FRUITS AND SEEDS IN Dodonea viscosa (L.) Jacquin (SAPINDACEAE)

\begin{abstract}
Morphological, structural and development features of fruits and seeds of Dodonea viscosa (L.) Jacquin (Sapindaceae) were described and illustrated emphazing the seed coat and embryo.
\end{abstract}

Index terms: morphology, pericarp, Sapindaceae.

\section{INTRODUÇÃO}

Os estudos com ênfase nas estruturas de frutos e sementes, especialmente nos envoltórios, antigamente restringiam-se às plantas cultivadas de interesse econômico ou a estrutura do fruto maduro. Mais recentemente, as alterações estruturais em desenvolvimento de unidades de dispersão de espécies, estão sendo observadas. Porém, esses estudos com espécies nativas de matas brasileiras ainda são escassos.

Segundo Corner (1976) existe grande necessidade de revisar a estrutura dos frutos e sementes de modo a atender
${ }^{1}$ Submetido em 21/03/2007. Aceito para publicação em 22/12/2007. ${ }^{2}$ Professor Adjunto, Departamento de Botânica, Instituto de Biociências,
UNESP, CP. 199, CEP 13506-900 Rio Claro, SP, Brasil, aapaoli@rc.unesp. br. Apoio financeiro CNPq e bolsista do CNPq. ${ }^{3}$ Bióloga. 
as afinidades específicas dentro dos gêneros, bem como as afinidades genéricas.

As estruturas morfológicas de um embrião maduro, assim como a posição que ocupa dentro da semente são tão distintas entre os diferentes grupos de plantas que podem ser seguramente utilizadas para a identificação de famílias, gêneros e até espécies (Toledo e Marcos Filho, 1977). Sabese que tanto as características externas quanto as internas das sementes, constituem um critério bastante seguro para a identificação, pois são pouco modificados pelo ambiente (Gunn, 1972).

A família Sapindaceae compreende 120 gêneros com mais de 1000 espécies, distribuídas por todos os trópicos (Reitz, 1980). Segundo Schultz (1985), são 1100 espécies pertencentes a regiões tropicais e subtropicais. $\mathrm{O}$ gênero Dodonea engloba 53 espécies, das quais 49 são da Austrália, uma do Hawai, uma de Madagascar, uma da Flórida e $D$. viscosa, em todas as regiões tropicais.

D. viscosa (L.) Jacq., conhecida vulgarmente como vassoura-vermelha, vassourão-vermelho, faxina-vermelha, erva-de-veado e vassoura-do-campo, é uma árvore ou um arbusto de 2,0 a 2,8m de altura, dotada de copa arredondada e rala. É uma planta decídua, heliófita, seletiva xerófita com flores apícolas. Ocorre de São Paulo ao Rio Grande do Sul, nas costas litorâneas desde a restinga até o alto da Serra do Mar. Suas folhas são utilizadas na medicina contra cólicas flatulentas, reumatismo, gota, várias doenças venéreas e febres. A casca tem emprego nas preparações de banhos adstringentes. A espécie possui potencial para arborização, principalmente, de ruas estreitas sob redes elétricas. Também fornece lenha para queimar. É uma planta pioneira e de rápido crescimento, sendo recomendada para a composição de reflorestamento heterogêneos com objetivos ecológicos (Schultz, 1985; Lorenzi, 1992).

Devido à importância econômica, paisagística e ecológica desta espécie, foi efetivado um estudo morfoanatômico e do desenvolvimento dos frutos e das sementes, obtendo informações sobre a biologia para melhor conhecimento da espécie, além de, fornecer subsídios para solucionar problemas de ordem taxonômica.

\section{MATERIAL E MÉTODOS}

O material botânico de Dodonea viscosa (L.) Jacquin, constou de flores e frutos em diferentes estágios de desenvolvimento. O material foi coletado de vários indivíduos junto ao arboreto do Centro Universitário Hermínio Ometto (UNIARARAS), no município de Araras (SP) e transportado em sacos plásticos para o laboratório de anatomia do IB/ UNESP/Rio Claro.

No laboratório, o material foi examinado à fresco e as medições nos frutos e nas sementes foram efetuadas em amostras de 50 com auxílio de um paquímetro, registrandose as médias.

Para o estudo anatômico dos frutos e das sementes em diferentes estágios de desenvolvimento, foram efetuadas secções transversais, longitudinais e paradérmicas à mão livre, com auxílio de lâmina de barbear comum ou utilizandose micrótomo rotatório.

$\mathrm{Na}$ obtenção de lâminas semi-permanentes, os cortes realizados à mão livre foram corados com safrablau (Safranina mais Azul de Astra), segundo técnica descrita por Gerlach (1969) e montados em gelatina glicerinada.

As lâminas permanentes foram confeccionadas com peças fixadas e o material incluído em glicol metacrilato, seguindo-se a técnica descrita por Guerrits (1991). O material foi seccionado em micrótomo rotativo manual, as secções coradas com azul de toluidina a $0,05 \%$ e em tampão acetato, pH 4,7 (Feder e O’Brien, 1968) e montadas em resina sintética.

Os desenhos referentes aos aspectos morfológicos de fruto foram obtidos com auxílio de estereomicroscópio adaptado a uma câmara clara.

As fotomicrografias referentes aos aspectos anatômicos dos frutos e das sementes foram obtidas com auxílio de um fotomicroscópio da Olymphus e os desenhos com microscópio acoplado à câmara clara, projetando-se uma lâmina micrométrica, nas mesmas condições ópticas utilizadas para cada caso.

\section{RESULTADOS}

\section{Morfologia do fruto e da semente}

Dodonea viscosa apresenta-se em geral como uma árvore de pequeno porte (Figura 1); os frutos completamente maduros são secos, deiscentes, tipo cápsula septifraga, com 3 alas, com pericarpo de consistência membranácea, de coloração pálea e medindo $1,5 \mathrm{~cm}$ de comprimento por $1,0 \mathrm{~cm}$ de largura (Figuras 2, 3). 
FIGURA 1. Aspecto da planta de Dodonea viscosa (L.) Jacq. com inflorescência e frutos maduros.

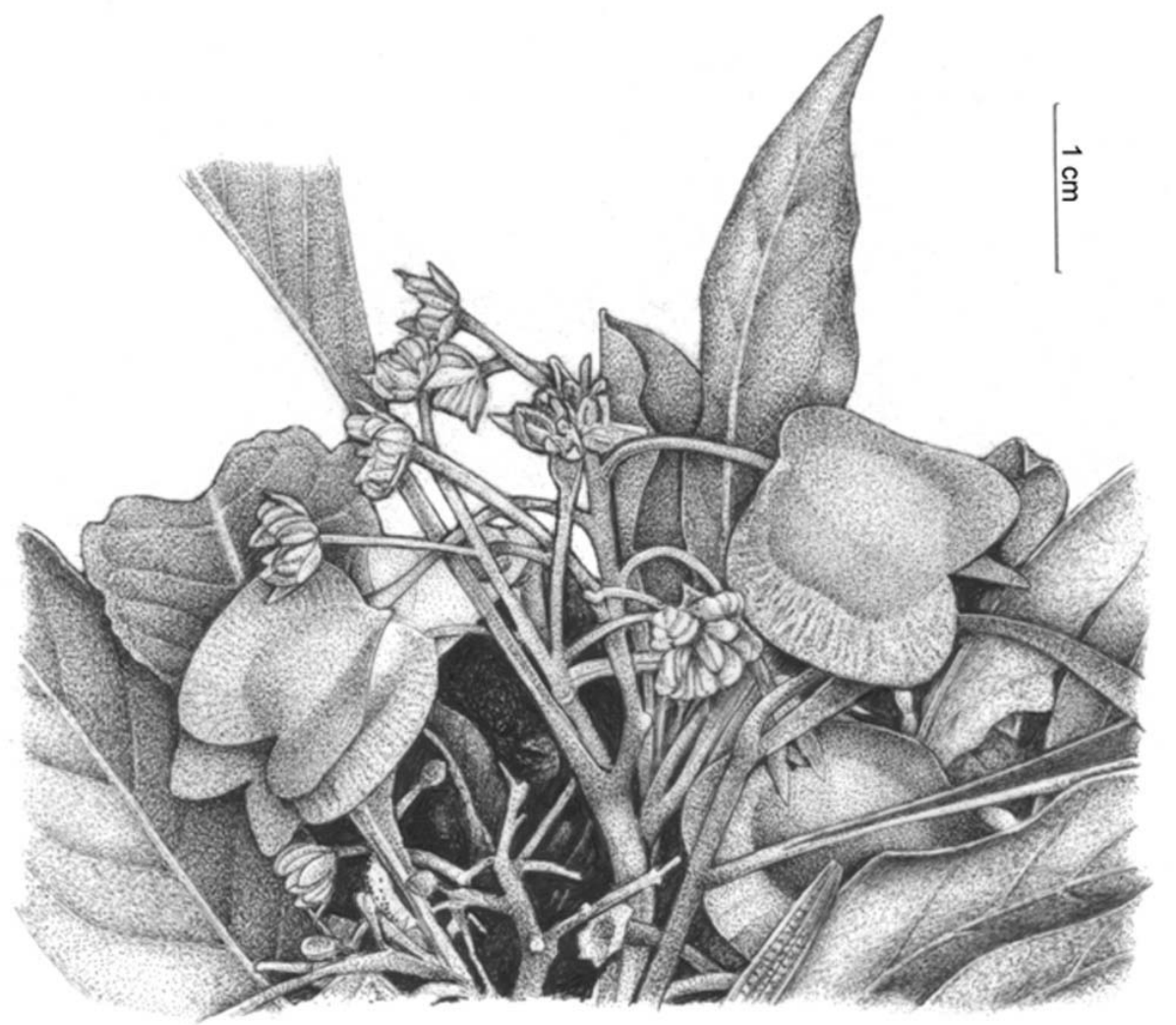

FIGURA 2. Fruto e semente de Dodonea viscosa (L) Jacq.:

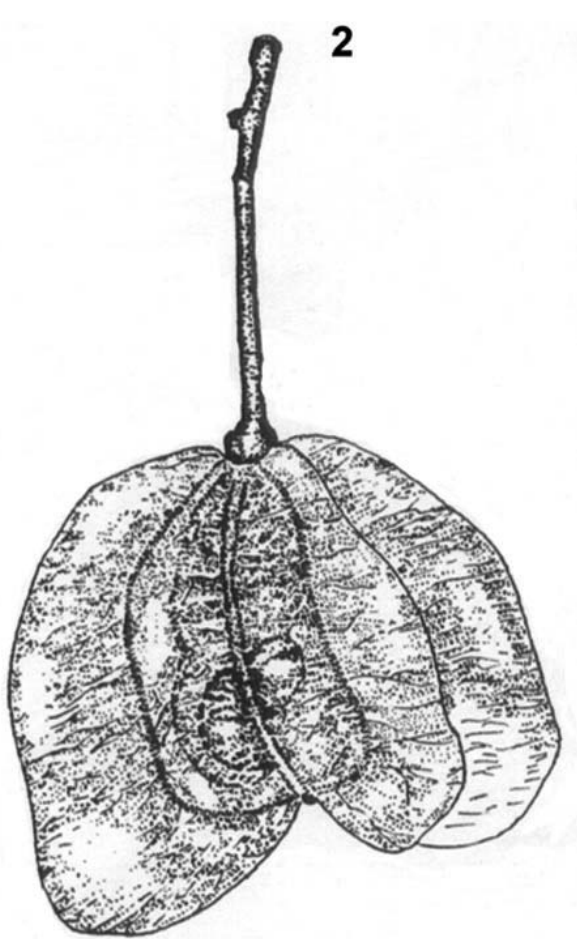

$\mathrm{a}$ - arilo, $\mathrm{c}$ - cotilédones, $\mathrm{h}$ - hilo.
FIGURA 3. Aspecto externo do fruto.

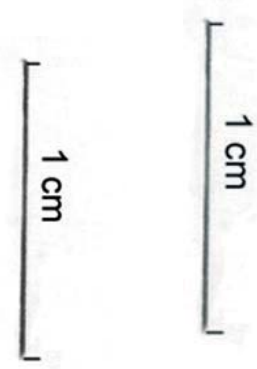

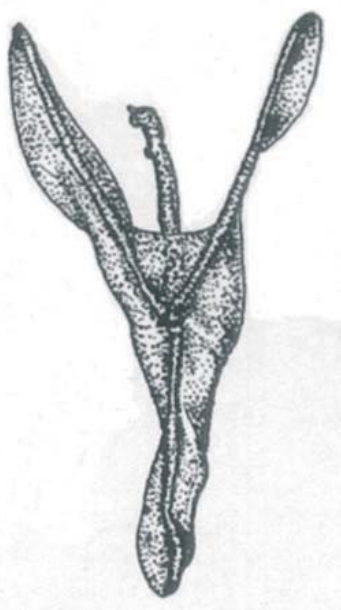

$\mathrm{a}$ - arilo, $\mathrm{c}$ - cotilédones, $\mathrm{h}$ - hilo. 
As sementes variam de 4 a 8 por fruto, são ovóides, com testa de coloração preta, lisa, brilhante e medem em geral 2,0mm de diâmetro (Figuras 4, 5). A região do hilo é envolvida por um arilo vestigial de coloração amarelada. A semente é exalbuminosa e o embrião é longo, estreito, com cotilédones espiralados e do tipo circinado, o eixo hipocótiloradícula é curto (Figuras 6,7).

FIGURA 4 . Aspecto externo da semente, evidenciando a região do hilo e o arilo.

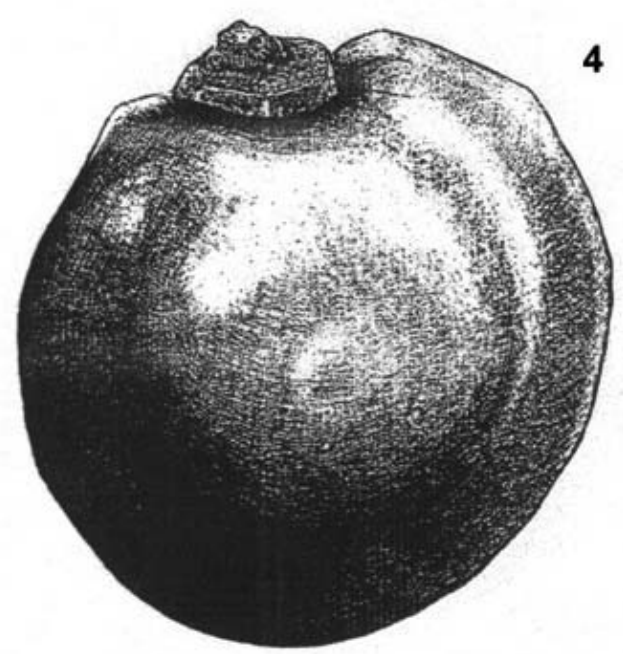

$\mathrm{a}$ - arilo, $\mathrm{c}$ - cotilédones, $\mathrm{h}$ - hilo.

FIGURA 5 . Aspecto externo da semente, evidenciando a região do hilo e o arilo.

5

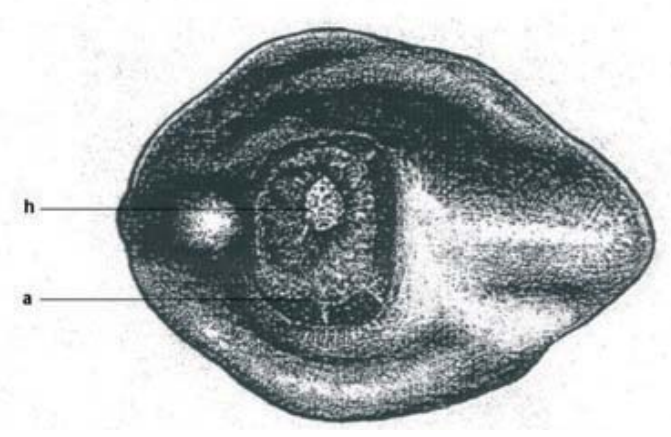

$\mathrm{a}$ - arilo, c - cotilédones, $\mathrm{h}-$ hilo.
FIGURA 6. Seção longitudinal da semente.

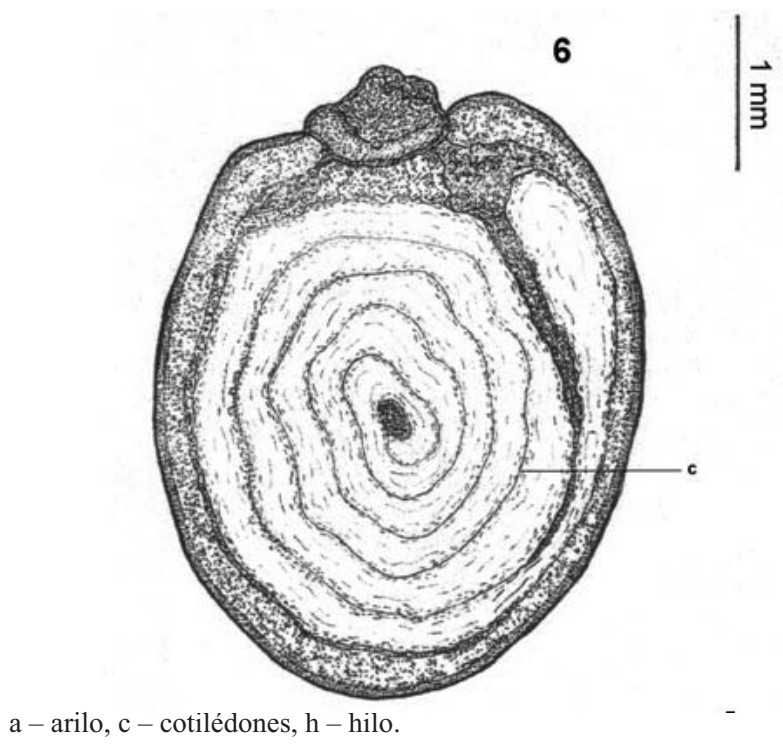

FIGURA 7. Embrião circinado.
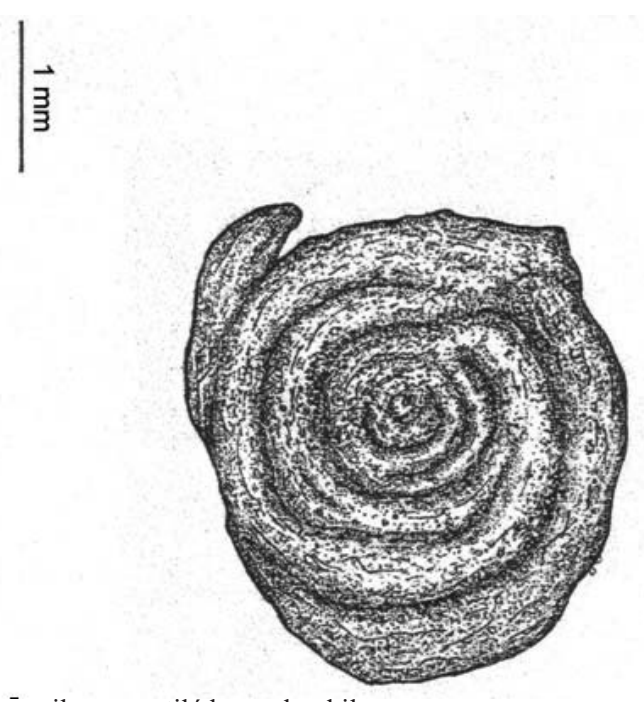

$\mathrm{a}$ - arilo, $\mathrm{c}-$ cotilédones, $\mathrm{h}$ - hilo.

\section{Anatomia do desenvolvimento do fruto}

Ovário (Figuras 8, 10,12): é súpero, tricarpelar, trilocular, com duas fileiras de óvulos por lóculo. A epiderme externa é unisseriada recoberta por cutícula, apresenta estômatos e numerosos tricomas (tipo: pêlos peltados e simples unicelulares). O mesofilo ovariano é constituído por parênquima ( 6 a 7 camadas) e ocorrem feixes vasculares. A epiderme interna do ovário é unisseriada com células aproximadamente retangulares, em secção transversal, e revestidas por cutículas. 
FIGURAS 8, 10 e 12 . Ovário e fruto bem jovem de Dodonea viscosa (L.) Jacq.: 8-10-12 - seção transversal do ovário mostrando numerosos tricomas e os lóculos com óvulos;

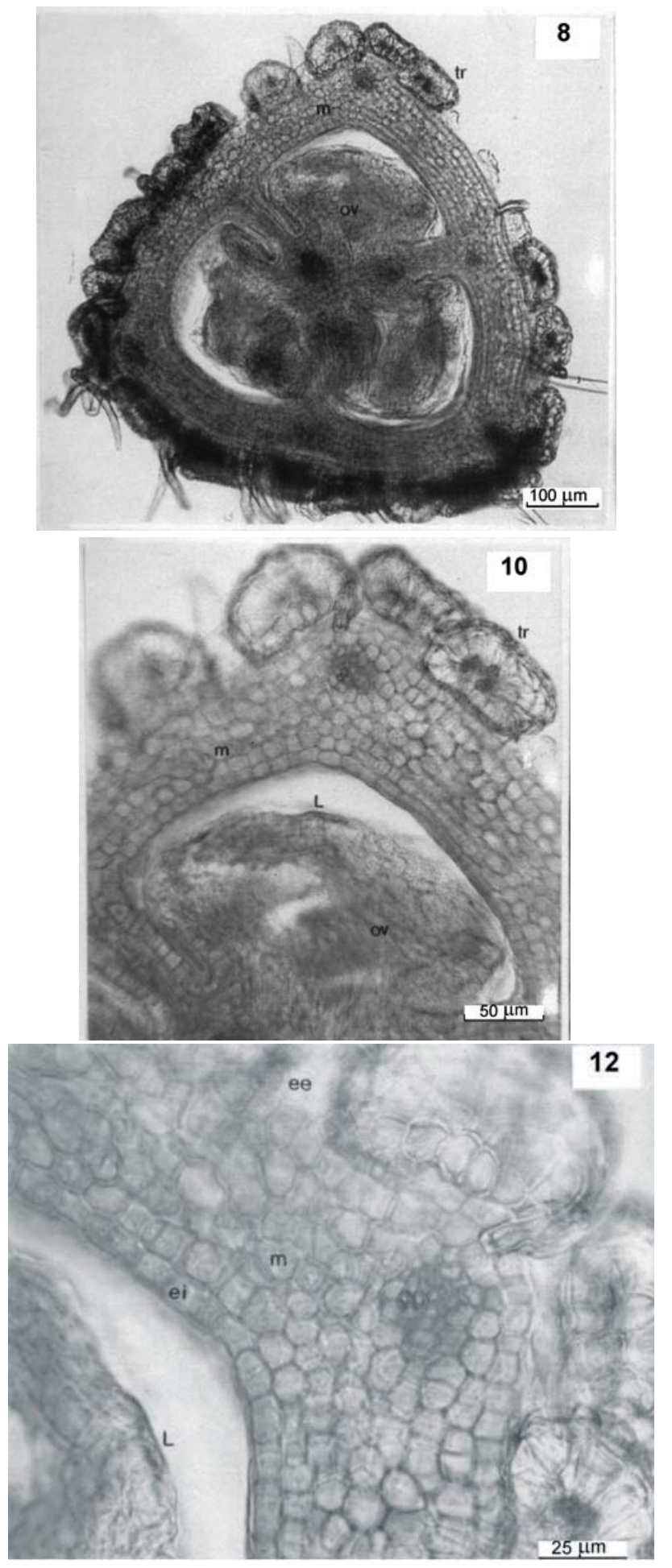

Estrutura do pericarpo: O fruto bem jovem (Figuras 11, 13) possui epiderme externa unisseriada com estômatos e tricomas (tipo: pêlo peltados e pêlos simples unicelulares); região parenquimática com feixes vasculares e drusas. Neste estágio já é possível observar o início de expansão aliforme do tegumento (Figuras 9, 11). A diferenciação das três regiões do pericarpo (exo, meso e endocarpo), durante o desenvolvimento do fruto é pouco acentuada. No fruto mais desenvolvido, mas ainda jovem, o mesocarpo que é constituído de células parenquimáticas e derivado do mesofilo ovariano, apresenta duas regiões: a externa, constituída de células amplas de paredes espessadas; a interna, com células menores, alongadas tangencialmente, sendo que na primeira camada desta região, ocorrem muitos idioblastos contendo drusas. O endocarpo, representado pela epiderme interna é unisseriado, glabro e desprovido de estômatos e possui cutícula revestindo a parede periclinal voltada para a cavidade seminal (Figuras 14, 15). A vascularização do fruto é feita por feixes colaterais que estão localizados no mesocarpo externo. No fruto maduro (Figuras 16 a 20) o epicarpo não sofre praticamente alterações, apenas um decréscimo acentuado no número de tricomas. A região do mesocarpo interno é constituída de 3 a 4 camadas de células parenquimáticas e apresenta-se neste estágio com fibras esclerenquimáticas de paredes lignificadas. O endocarpo continua sendo unisseriado.

\section{FIGURAS 9. Seção transversal do fruto bemjovem, evidenciando a formação das alas e o feixe vascular no mesocarpo.}

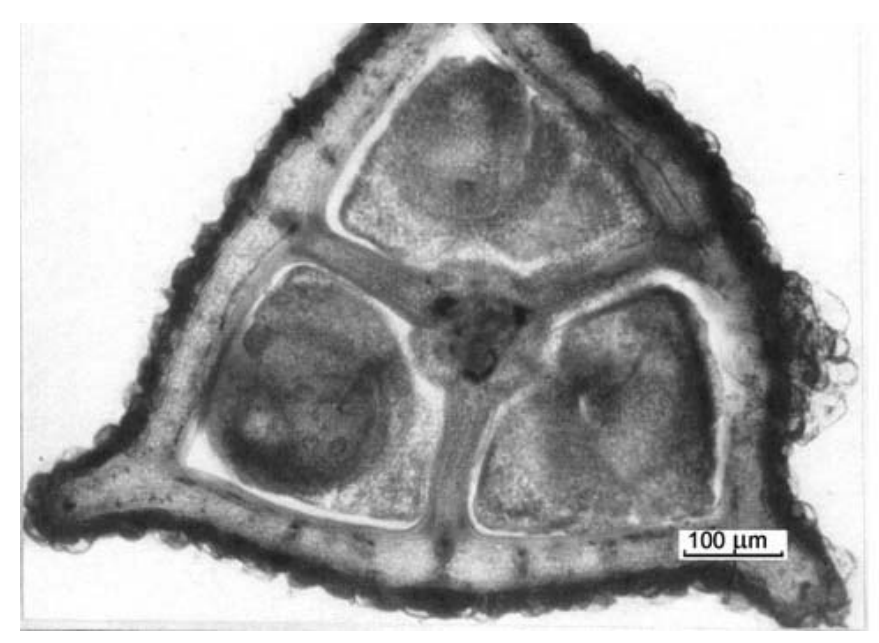

ee - epiderme externa, ei - epiderme interna, ED - endocarpo, EP epicarpo, fv - feixe vascular, L - lóculo, $\mathrm{m}$ - mesofilo, ME - mesocarpo, ov - óvulo, tr - tricoma. 
FIGURAS 11 e13. Seção transversal do fruto bemjovem, evidenciando a formação das alas e feixe vascular no mesocarpo.
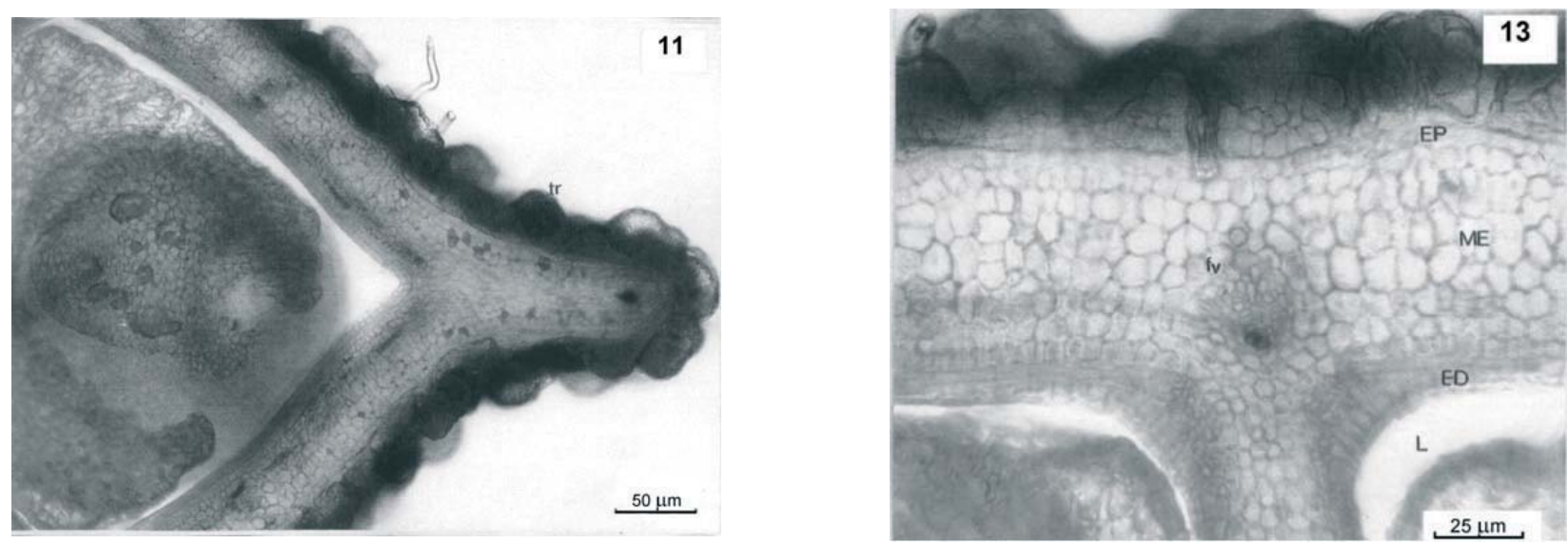

ee - epiderme externa, ei - epiderme interna, ED - endocarpo, EP - epicarpo, fv - feixe vascular, L - lóculo, m - mesofilo, ME - mesocarpo, ov - óvulo, $\operatorname{tr}$ - tricoma.

FIGURAS 14 a 18 . Fruto jovem e maduro de Dodonea viscosa (L.) Jacq.: 14-15 - seções transversais do fruto jovem evidenciando as duas regiões do mesocarpo; 16-18 - seções transversais do fruto maduro, evidenciando o mesocarpo interno fibroso; 17 - seção paradérmica do epicarpo com estômatos.

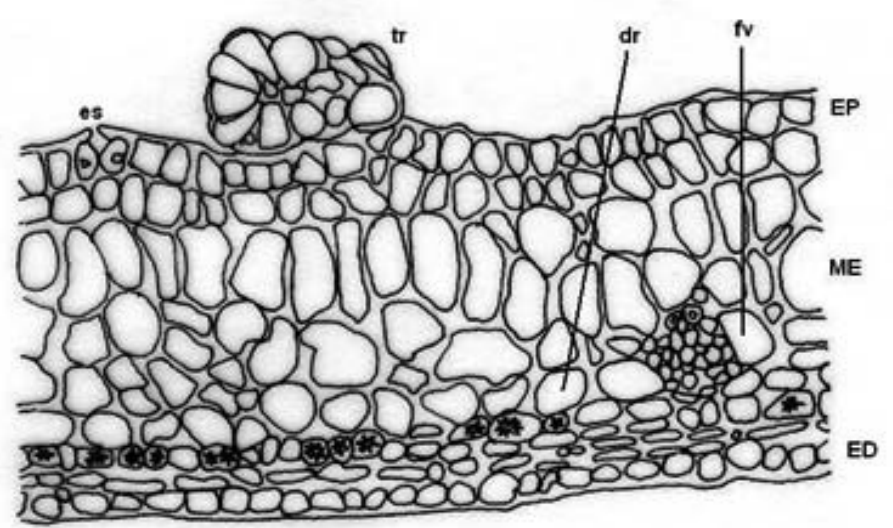

14

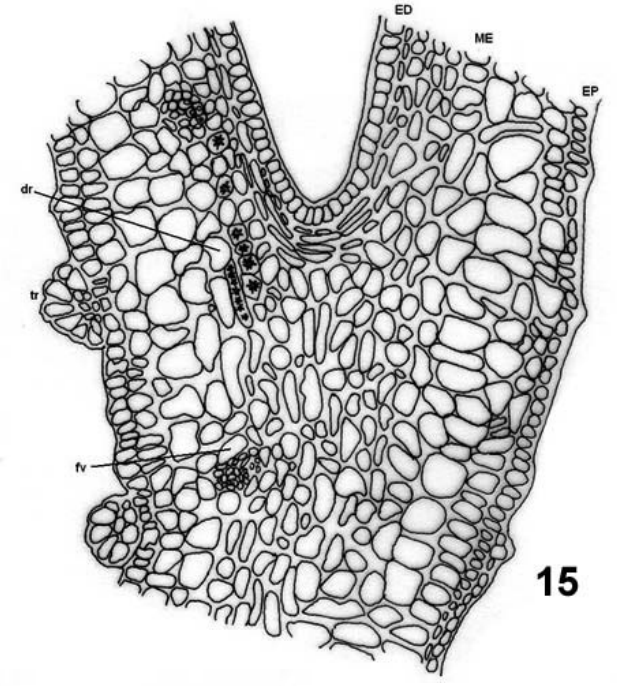

15

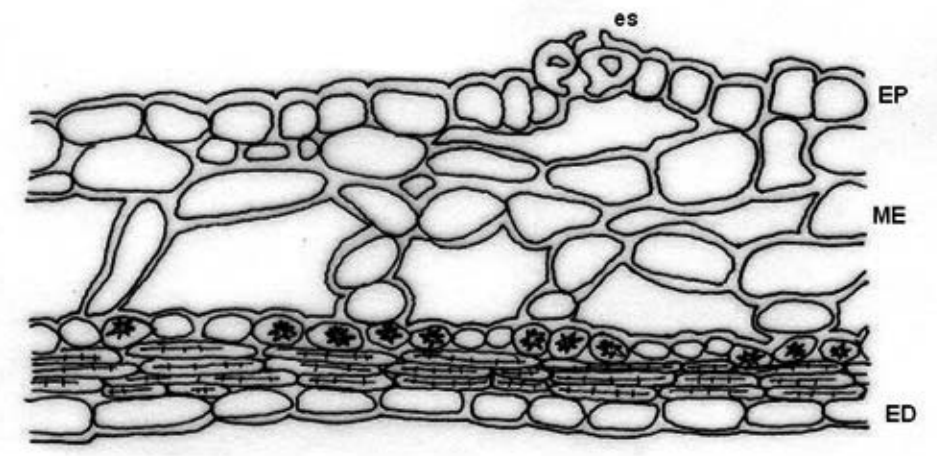

dr - drusa, ED - endocarpo, EP - epicarpo, es - estômato, f - fibras, fv - feixe vascular, ME - mesocarpo, tr - tricoma. 
17
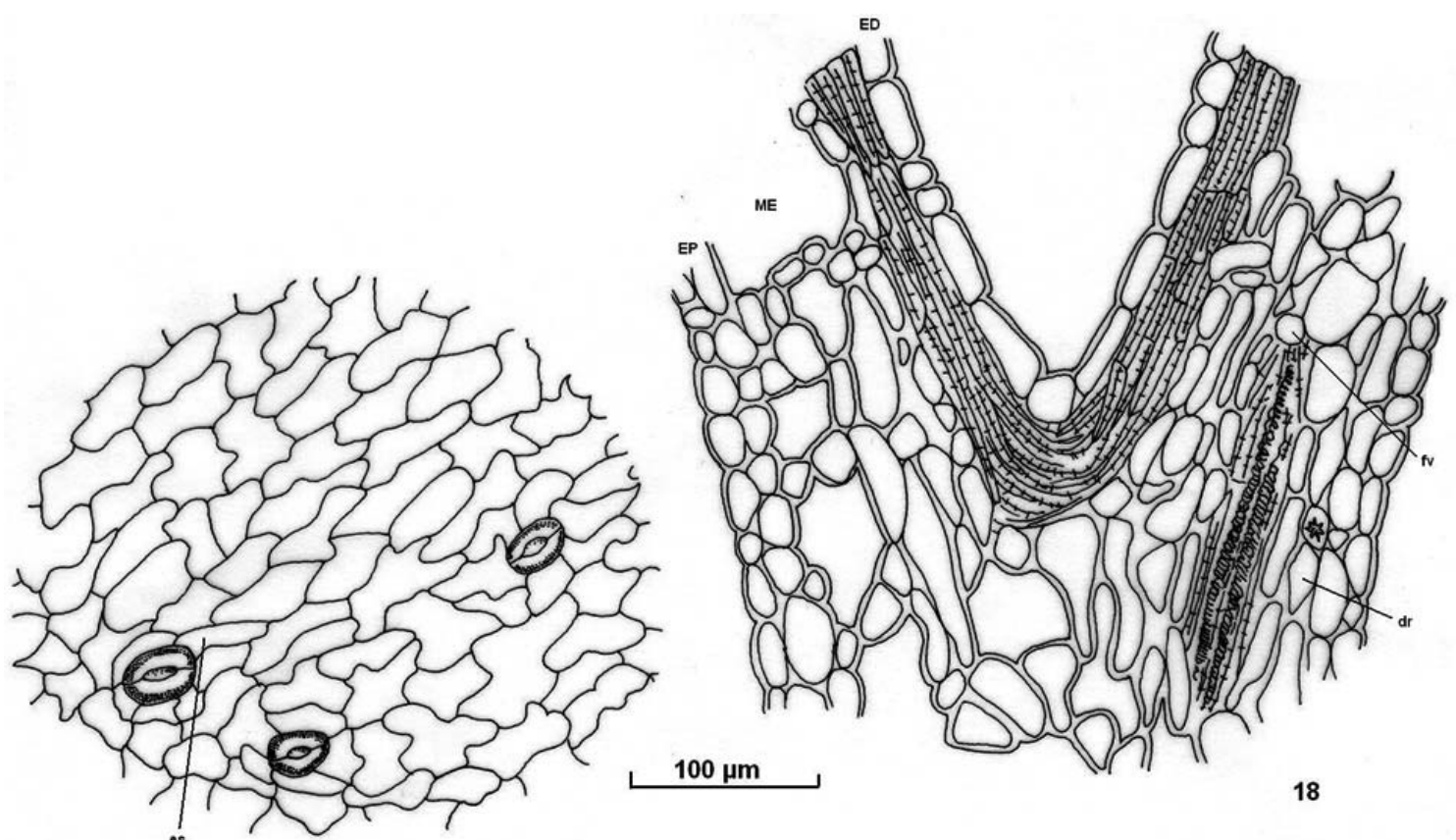

$\mathrm{dr}$ - drusa, ED - endocarpo, Ë - epicarpo, es - estômato, f - fibras, fv - feixe vascular, ME - mesocarpo, tr - tricoma.

FIGURAS 19 e 20 . Fruto maduro de Dodonea viscosa (L.) Jacq. em seção transversal.

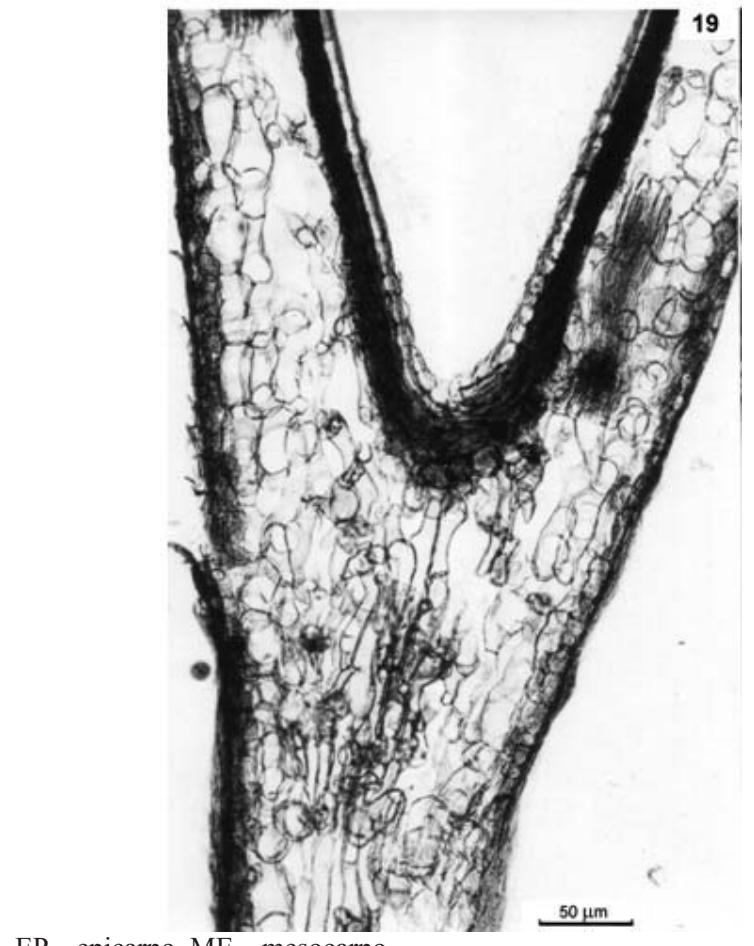

EP - epicarpo, ME - mesocarpo.

\section{Anatomia do desenvolvimento da semente}

O óvulo é anacampilótropo, bitegumentado, crassinucelado e apresenta obturador placentário semelhante a uma pequena aba. $\mathrm{O}$ tegumento externo é constituído de 2 a

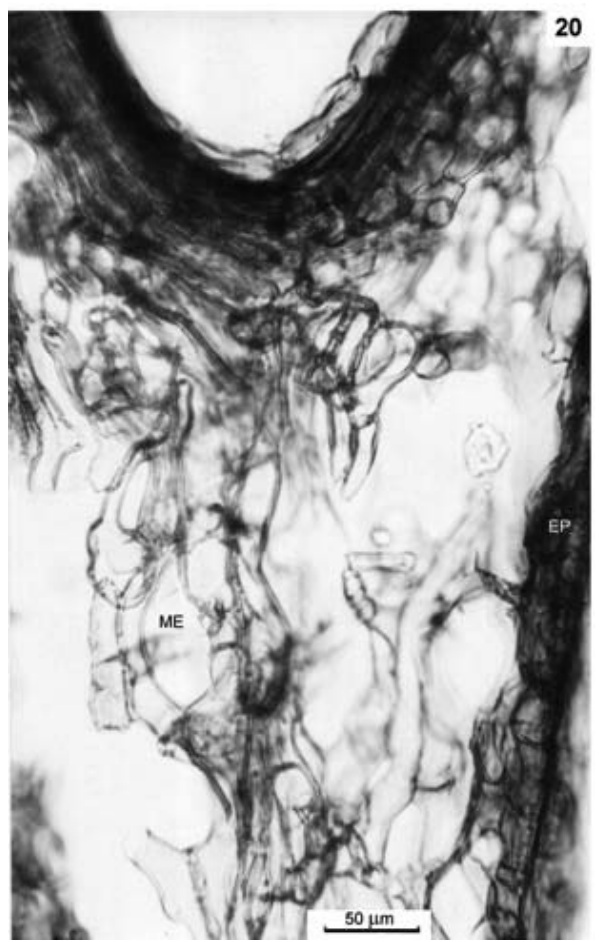

3 camadas de células e o interno por três camadas de células (Figura 21). Ambos os tegumentos limitam a micrópila, existindo ainda entre o tegumento interno e o nucelo uma cutícula interna. Com o desenvolvimento da semente ocorre 
um acentuado aumento no número de estratos celulares no tegumento externo, caracterizando-se a testa como multiplicativa (Figuras 22, 23). Na semente bem jovem, na exostesta originada da epiderme externa do óvulo, observa-se o início de alongamento das células (Figura 22), constituindose na semente ainda jovem, uma camada de células em paliçada, radialmente alongadas (Figura 25). A mesotesta apresenta duas regiões distintas: a externa, constituída de várias camadas de células parenquimáticas de parede bem fina, contendo muitos grãos de amido e a mesotesta interna aerenquimática. $\mathrm{O}$ tégmem apresenta-se constituído de três camadas de células pequenas e cubóides (Figuras 24, 25).

FIGURAS 21 a 24. Óvulo, semente bem jovem e semente madura de Dodonea viscosa (L.) Jacq.: 21 - seção longitudinal, evidenciando em detalhe um óvulo; 22-23 - semente bem jovem em duas posições diferentes, mostrando o embrião em secção transversal (22) e longitudinal (23), evidenciando a presença de obturador; 24 - seção transversal da semente quase madura com presença de exotesta em paliçada.
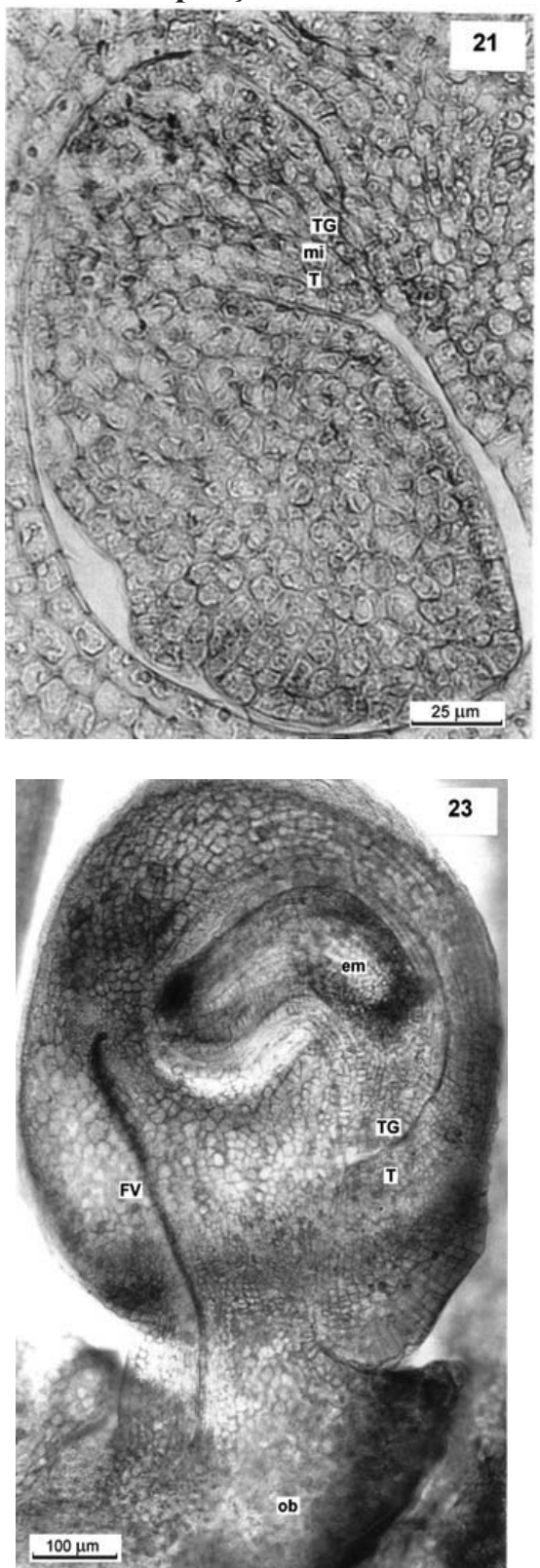
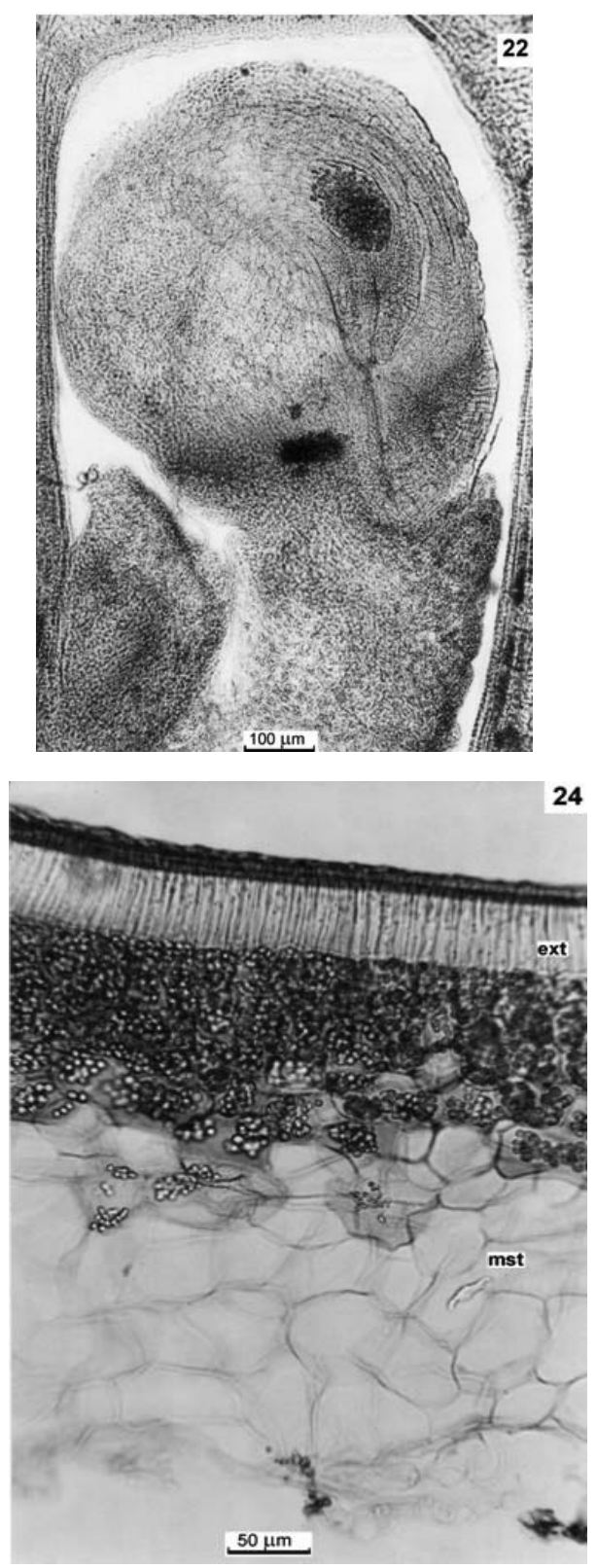

em - embrião, ext - exotesta, fv - feixe vascular, mi - micrópila, mst - mesotesta, ob - obturador, T - testa, TG - tégmen. 
FIGURA25. Semente quase madura e madura de Dodonea viscosa (L.) Jacq.

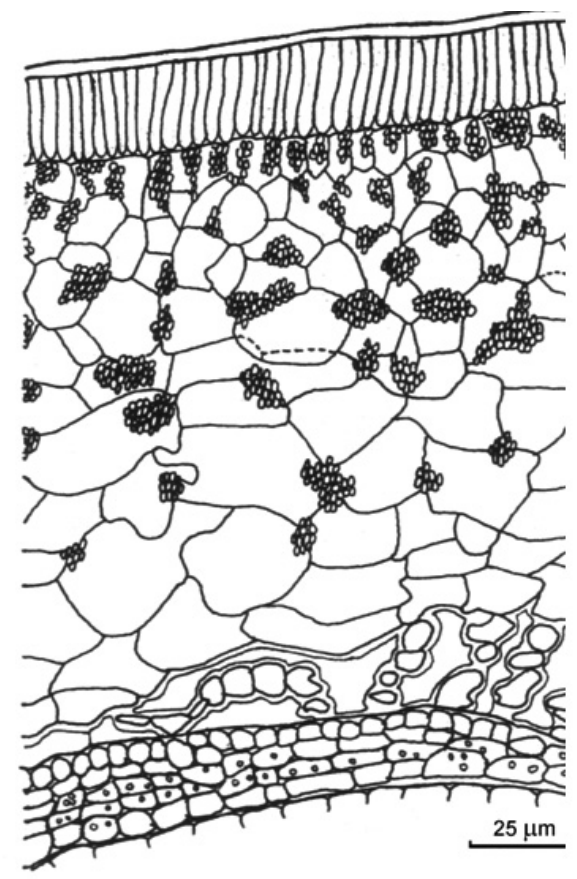

c - cutícula, ent - endotesta, ext - exotesta, mst - mesotesta, TG tégmen.

$\mathrm{Na}$ semente madura (Figura 26) a testa é composta por várias camadas de células, apresentando exotesta constituída inteiramente por macroesclereídes, alongadas e de paredes bem espessadas na porção superior. A mesotesta continua dividida em parte externa, agora com células pouco alongadas, de paredes espessadas e parte interna amassada. Tégmem reduzido totalmente amassado.

\section{FIGURA 26. Seção transversal da semente madura.}

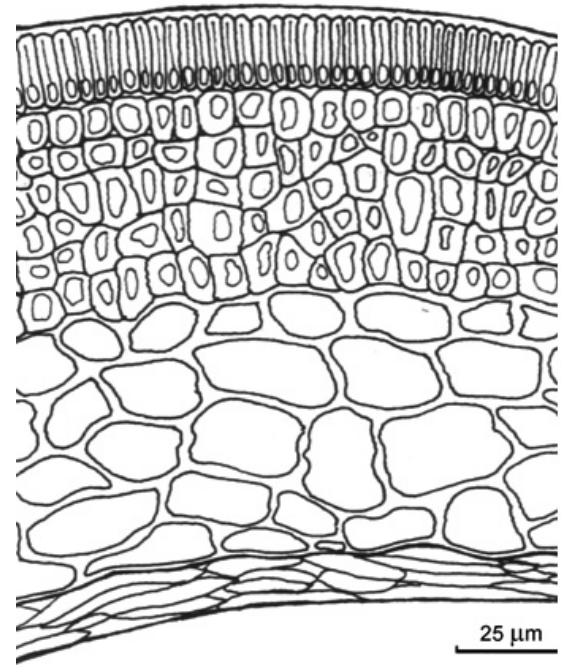

\section{DISCUSSÃO}

As definições do exocarpo, mesocarpo e endocarpo variam de acordo com cada autor. Os autores modernos, na sua maioria, preferem usar os termos exo e endocarpo em sentido amplo, incluindo as epidermes externa e interna, respectivamente, e alguns dos tecidos subepidérmicos (Roth, 1977). Segundo Fahn (1978), a separação do pericarpo em três camadas facilita a descrição anatômica, mas elas não representam camadas distintas do ponto de vista de sua origem. Em Dodonea viscosa a separação em três camadas facilitou a descrição, sendo que o mesocarpo, no fruto maduro ainda é diferenciado em duas partes distintas, sendo a inferior transformada em fibras.

Segundo a classificação de Barroso et al. (1999), o fruto de Dodonea viscosa é incluído como capsular e apresenta valvas aladas. Spjut (1944) descreveu o fruto de Dodonea como uma sâmara. Roosmalen (1985) relata para Sapindaceae a ocorrência de frutos tipo cápsula (Cupania, Dodonea, Matayba, Paullinia, Pseudima e Vouarana), baga (Talisia) ou esquizocarpo (Allophyllus, Sapindus, Serjania, Thinouia, Toulicia e Urvillea).

Os óvulos de Sapindaceae são referidos como anátropo ou campilótropo, bitegumentado e crassinucelados, com duas fileiras de óvulos por lóculo (Corner, 1976).

Em Dodonea viscosa foi verificado que o óvulo é anacampilótropo e possui obturador placentário. Segundo Corner (1976), o obturador é freqüente em Sapindaceae, sendo uma estrutura arredondada de origem placentária ou funicular que recobre ou não a micrópila. Este autor relatou a presença de obturador em Allopylus cobbe, Cardiospermum halicacabum, Dodonea viscosa e Nephelium lappaceum. Albiero et al. (2001) trabalhando com sementes de Sapindus saponarea L. e Nacif et al. (2001) num estudo com Litchi chinensis Sonn. cv. Brewster, ambas espécies pertencentes a Sapindaceae também relataram a ocorrência de obturador presente no óvulo. O obturador é uma estrutura especial que ocorre próximo a micrópila e tem a função principal de guiar o crescimento de tubo polínico, podendo ser de origem funicular, placentária ou de combinação das duas. Pode ser ainda, uma saliência coberta por tricomas secretores, ou simplesmente, uma região com epiderme papilosa. O obturador cresce através da micrópila e mantém conexão com o tecido transmissor ou com a epiderme secretora do canal estilar, sendo que após a polinização se degenera (Bouman, 1984).

No material do presente estudo constatou-se a presença de um obturador bem desenvolvido de origem 
placentária.

Corner (1976) afirmou que a presença de funículo bem desenvolvido é uma característica peculiar em muitasementes e sugeriu que, devido a este fato, arilos vestigiais poderiam ser encontrados. Em Dodonea viscosa foi encontrado um arilo vestigial na região do hilo, fato este observado por Barroso et al. (1999).

O número de tegumentos é um caráter embrionário mais importante, uma vez que sementes bitegumentadas mais comuns são consideradas primitivas (Corner, 1976). Em Dodonea viscosa a semente é bitegumentada, sendo considerada testal, uma vez que a testa é multiplicativa e exotestal por ser a camada mais externa da testa, constituída pela camada de macroesclereídes, sendo considerada como a principal camada mecânica da testa. Esta classificação da semente levando-se em conta a principal camada mecânica é baseada no extenso trabalho de Corner (1976), sobre anatomia de sementes de dicotiledôneas.

\section{AGRADECIMENTOS}

Ao Conselho Nacional de Desenvolvimento Científico e Tecnológico (CNPq), pelo auxílio à pesquisa.

\section{REFERÊNCIAS}

ALBIERO, A.L.M.; BACCHI, E.M.; MOURÃO, K.S.M. Caracterização anatômica das folhas, frutos e sementes de Sapindus saponaria L. (Sapindaceae). Acta Scientiarum, Maringá, v.23, n.2, p.549-560, 2001.

BARROSO, G.M.; MORIM, M.P.; PEIXOTO, A.L.; ICHASSO, C.L.F. Frutos e sementes: morfologia aplicada à sistemática de dicotiledôneas. Viçosa: UFV, 1999. 443p.

BOUMAN, F. The ovule In: JOHR, B.M. (Ed.). Embriology of angiosperms. Berlin: Heidelberg Springer Verlag, 1984. p.123-157.

CORNER, E.J.H. The seeds of dicotyledones. Cambridge: Cambridge University Press, 1976. v.1, p.331
CORNER, E.J.H. The seeds of dicotyledones. Cambridge: Cambridge University Press, 1976. v.2. p.552

FAHN, A. Anatomia vegetal. Madrid: H. Blume, 1978. 643p.

FEDER, N.; O'BRIEN, T.P. Plant microthecnique: some principles and new methods. American Journal of Botany, Stanford, v.55, n.1, p.123-142, 1968.

GERLACH, G. Botanisch microtecnik, eine einführung. Stuttgart: George Thiem, 1969. 198p.

GUERRITS, P.O. The application glycol methacrylate in histotecnology: some fundamental principles. Groningen: Department of Anatomy and Embryology State University Groningen, 1991.243p.

GUNN, C.R. Seed collecting and identification. In: KOZLOWSKI, T.T. Seed biology. New York: Academic Press, p.1-20, 1972.

LORENZI, H. Árvores brasileiras: manual de identificação e cultivo de plantas arbóreas do Brasil. Nova Odessa: Plantarium, 1992. 352p.

NACIF, S.R.; PAOLI, A.A.S.; SALOMÃO, L.C.C. Morphological and anatomical development of the litchi fruit (Litchi chinensis Sonn. Cv. Brewster). Fruits, v.56, n.4, p.225-233, 2001.

REITZ, R. Flora ilustrada catarinense. Sapindáceas. Itajaí: Herbário Barbosa Rodrigues, 1980. 160p.

ROOSMALEN, M.G.M. Fruits of the Guianan flora. Utrecht: Institut of Systematic Botany: Utrecht University, 1985. 483p.

ROTH, I. Fruits of angiosperms. Berlin: Gebruder Borntraeger, 1977. 675p.

SCHULTZ, A.R.H. Introdução à botânica sistemática. 5.ed. Porto Alegre: EDUFRGS, 1985. v.2, 414p.

SPJUT, R.W. A systematic treatment of fruit types. New York: Memoirs of the New York Botanical Garden, 1994. $181 \mathrm{p}$.

TOLEDO, F.F.; MARCOS-FILHO, J. Manual de sementes: tecnologia da produção. São Paulo: Agronômica Ceres, 1977. 224p. 